\title{
Gender perspective in medicine: a vital part of medical scientific rationality. A useful model for comprehending structures and hierarchies within medical science Gunilla Risberg*, Katarina Hamberg and Eva E Johansson
}

Address: Department of Public Health and Clinical Medicine, Section of Family Medicine, Umeå University, NUS, S-90185 Umeå, Sweden

Email: Gunilla Risberg* - gunilla.risberg@fammed.umu.se; Katarina Hamberg - Katarina.Hamberg@fammed.umu.se; Eva E Johansson - eva.johansson@fammed.umu.se

* Corresponding author

Published: 24 August 2006

BMC Medicine 2006, 4:20 doi:10.1/86/174|-70|5-4-20
Received: 16 March 2006

Accepted: 24 August 2006

This article is available from: http://www.biomedcentral.com/I74I-70I5/4/20

(c) 2006 Risberg et al; licensee BioMed Central Ltd.

This is an Open Access article distributed under the terms of the Creative Commons Attribution License (http://creativecommons.org/licenses/by/2.0), which permits unrestricted use, distribution, and reproduction in any medium, provided the original work is properly cited.

\begin{abstract}
Background: During the past few decades, research has reported gender bias in various areas of clinical and academic medicine. To prevent such bias, a gender perspective in medicine has been requested, but difficulties and resistance have been reported from implementation attempts. Our study aimed at analysing this resistance in relation to what is considered good medical research.
\end{abstract}

Method: We used a theoretical model, based on scientific competition, to understand the structures of scientific medicine and how they might influence the resistance to a gender perspective in medicine. The model was originally introduced to discuss how pluralism improves rationality in the social sciences.

Results: The model provided a way to conceptualise different fields of research in medicine: basic research, applied research, medical philosophy, and 'empowering' research. It clarified how various research approaches within medicine relate to each other, and how they differ and compete. It also indicated why there might be conflicts between them: basic and applied research performed within the biomedical framework have higher status than gender research and other research approaches that are performed within divergent research paradigms.

Conclusion: This hierarchy within medical research contributes to the resistance to a gender perspective, causing gender bias and making medical scientific rationality suboptimal. We recommend that the theoretical model can be applied in a wider medical context when different and hierarchically arranged research traditions are in conflict. In this way, the model might contribute to shape a medical community where scientific pluralism is acknowledged to enlarge, not to disturb, the scientific rationality of medicine.

\section{Background}

The concept of gender has been used in the social and humanistic sciences since the 1960s. It was originally introduced to designate how different societies and cultures interpret biological sex [1]. It refers to the constantly ongoing social construction of what is considered 'feminine' and 'masculine' ('doing gender'), based on power and sociocultural norms about women and men [2-4]. 
Thus gender is a wider concept than sex, [3] and a gender perspective in medicine implies that living conditions, positions in society and societal expectations about 'femininity' and 'masculinity' should be considered along with biology in professional relationships, as well as when theorising about women and men. Unawareness of gender aspects among health-care professionals and medical researchers can lead to gender bias.

Such bias has been described during the past decades in research from various areas of clinical and academic medicine. Unjustified differences in the investigation and treatment of male and female patients have been identified, most abundantly and ever recurrently in coronary heart disease [5-7], but also in other conditions such as kidney disease [5], depression [8], HIV/AIDS [9], colorectal cancer [10], neck pain [11] and irritable bowel syndrome[12]. There are also reports of discrimination and harassment based on gender among medical students [13], physicians [14], medical faculty $[14,15]$ and medical researchers $[15,16]$.

To prevent and avoid gender bias, there are good reasons for a gender perspective to be included in medicine in the same way as perspectives regarding social class, ethnicity, and age. However, in reports from attempts to introduce gender issues in clinical medicine, medical research and medical curricula, difficulties and resistance have been experienced and described. For example, in medical research and education, the term 'gender' is often wrongly used as being synonymous with biological sex [17]. Sometimes 'sex' is simply replaced by 'gender', and used as a variable even in experiments on animals [18]. Analyses of medical textbooks, training material and examination questions have revealed stereotypical gender patterns and even open patriarchal views [15,19-21]. Enduring and difficult work has been described when trying to address and change this [20-23]. Lack of interest in gender issues has been shown from students $[23,24]$ as well as from faculty. Interviews with course organisers at a medical school revealed that several of them found a gender perspective to be of little relevance in medicine; gender issues were considered subjective and unscientific [25]. In open answers from a questionnaire to physician teachers about gender issues, many comments were minimising, neutralising, and sometimes even denying the role of gender in professional relationships [26].

In this paper, we theorise about and try to understand this resistance to a gender perspective in medicine in relation to what is considered good and valid research in the medical society.

\section{Methods}

We used a theoretical model to explore and comprehend structures of scientific medicine and how they might influence the resistance to gender issues. The model was originally introduced by Johansson [27] to discuss pluralism and rationality of the social sciences. Johansson looks upon science as a social institution aiming at giving us a more 'truth-like' view of nature, man and society. He defines scientific rationality as the means to reach this 'truth-likeness'. The model was used to illustrate that a scientific field can embrace different kinds of research with different scientific rationalities.

One important presumption behind the theoretical model is that science as a social phenomenon is, like the rest of society, influenced by competition. For example, researchers compete for fame, resources and esteem. Four kinds of competition are described and related to each other in pairs. The first competition pair deals with the people to whom the research is addressed in the first place: to fellow researchers in the same field (actor-oriented) or to those who might benefit from the results of the research (public-oriented). The second competition pair deals with how the research is pursued: within (parallel competition) or outside (counter-competition) the prevailing paradigm. When social sciences were analysed through this competition model, Johansson distinguished four different research approaches, each with its own scientific rationality (Figure 1). In this paper, we have used the model to examine medicine.

\section{Results and discussion}

When applying the combinations in the model to medical science, we identified the following research areas in medicine (Figure 2): basic research, applied (clinical) research, medical philosophy and 'empowering' research.

\begin{tabular}{l|l|l|}
\multicolumn{1}{c}{} & \multicolumn{1}{l}{$\begin{array}{l}\text { Actor-oriented } \\
\text { competition }\end{array}$} & \multicolumn{1}{l}{$\begin{array}{l}\text { Public-oriented } \\
\text { competition }\end{array}$} \\
\cline { 2 - 3 } $\begin{array}{l}\text { Parallel } \\
\text { competition }\end{array}$ & $\begin{array}{l}\text { Basic science: } \\
\text { Normal scientific } \\
\text { rationality }\end{array}$ & $\begin{array}{l}\text { Applied science: } \\
\text { Technological rationality }\end{array}$ \\
\cline { 2 - 3 } $\begin{array}{l}\text { Counter- } \\
\text { competition }\end{array}$ & $\begin{array}{l}\text { Paradigm conflict: } \\
\text { Philosophical rationality }\end{array}$ & $\begin{array}{l}4 \\
\text { Paradigm conflict: } \\
\text { Political rationality }\end{array}$ \\
\hline
\end{tabular}

Figure I

Competition and rationality model modified from Johansson. From: Johansson I. Pluralism and rationality in the social sciences. Phil Soc Sci I99I, 2 I (4):427-43. 


\begin{tabular}{|c|c|c|}
\hline & $\begin{array}{l}\text { Actor-oriented } \\
\text { competition }\end{array}$ & $\begin{array}{l}\text { Public-oriented } \\
\text { competition }\end{array}$ \\
\hline $\begin{array}{l}\text { Parallel } \\
\text { competition } \\
\text { (biomedical } \\
\text { framework) }\end{array}$ & \begin{tabular}{|l|}
1 \\
Basic research \\
'Normal' (biomedical) \\
scientific rationality
\end{tabular} & $\begin{array}{l}2 \\
\text { Applied (clinical) research } \\
\text { Technological rationality }\end{array}$ \\
\hline $\begin{array}{l}\text { Counter- } \\
\text { competition } \\
\text { (paradigm } \\
\text { conflict) }\end{array}$ & \begin{tabular}{|l|}
3 \\
Medical philosophy (theory \\
of science) \\
Philosophical rationality
\end{tabular} & $\begin{array}{l}4 \\
\text { "Empowering" research } \\
\text { (e.g. consultation research } \\
\text { and gender research) } \\
\text { Political rationality }\end{array}$ \\
\hline
\end{tabular}

Figure 2

Johansson's model applied to medicine: different types of research and research rationalities in medicine related to different types of competition.

\section{The biomedical framework versus other research paradigms}

Basic and applied research is performed within the biomedical framework, the dominating paradigm in medicine. Researchers use the quantitative hypotheticodeductive method, with epistemological roots in positivism and logical empiricism. Knowledge is defined as facts that can be verified. Explanation and proof are sought. These traditional biomedical methods have been, and are, very successful in producing useful medical knowledge, but they are not suited for all types of medical research. For example, they are often not fitted to studies of 'soft' data such as patient experiences or patientdoctor interaction, which are important elements of clinical medicine. Nor can they help researchers to discover, interpret and understand the character and meaning of social phenomena, such as the reluctance to consider gender issues in medicine or to understand comprehensive processes in their contexts [28,29].

Medical researchers within medical philosophy and 'empowering' research recognise these limitations of the biomedical methods. They see paradoxes and medical anomalies, phenomena that do not comply with established biomedical explanations, for example, undefined musculoskeletal pain [30]. They adopt other research traditions, such as social constructivism, hermeneutics or phenomenology where knowledge is seen as interpreted, contextual and situated. The aim is to understand, not to prove. A paradigm conflict arises not only because of the epistemological difference from biomedicine, but also due to the character of the research subjects and because qualitative methods that are uncommon in the biomedical contexts are often used.

Actor-oriented versus public-oriented research in medicine Medical scientists within basic research and medical philosophy use a scientific language with a very specialised interdisciplinary terminology and a high theoretical abstraction in their research, which is often difficult to grasp for those who are not in the field. Thus, their primary scientific communication is with their fellow researchers in the same sector. In applied and 'empowering' research within medicine, on the other hand, researchers try to communicate with and address more directly those who might benefit from their scientific findings, as they are the ones that could evaluate the usefulness and efficacy of the research results.

\section{Scientific rationalities}

In the original theoretical model (Figure 1), the scientific rationalities emerging from the analysis are classified as normal scientific, technological, philosophical, and political, respectively. Considering the divergent patterns regarding competition outlined above, we find that the scientific approaches of medicine and their rationalities can be described as follows (Figure 2):

i) Basic medical research. Most researchers in this sector do their research in pre-clinical departments of, for example, cellular morphology, biochemistry, physiology, molecular biology or immunology. In their laboratories, they conduct experiments and test hypotheses to gain new knowledge. The results seldom have immediate application in clinical practice. This research often uses the traditional 'orthodox' biomedical design, which has dominated modern medical science since the late 19th century, thus applying the 'normal' scientific rationality within medicine.

ii) Clinical (applied) research. A considerable part of medical research is within this field. It is carried out in clinical, public health and epidemiological departments, and in primary health care. It represents a wide range of research subjects, for example, the prevention and more efficient treatment of global health threats such as HIV/AIDS, tuberculosis, malaria and cancer, and in the prevention and treatment of 'welfare disorders', including adiposity, diabetes and hypertension. The research rationality is technological in a wide sense. It encompasses not only technical issues such as investigation methods or techniques to distribute medical technology and expertise, but it also includes various types of medical treatment and care.

iii) Medical philosophy and theory of science. This research area is not very widely represented in the core of medical science. The research deals with with the humanistic side of medicine: our choices, decisions and actions, critical self-reflection, and widening of perspectives. Researchers also problematise the definition, production and development of knowledge, and the handling of possible biases. Such research can be found in medical ethics, 
medical sociology and medical anthropology, and in gender-theory studies. The philosophical rationality implies the performance of analyses to elucidate different alternatives, not to provide distinct and given answers.

iv) 'Empowering' research. An important purpose of this research approach in medicine is to empower subordinated and oppressed groups or individuals as one way to ensure better health. For example, researchers within this area pay attention to the importance of position, living conditions and life experiences for health and disease. The power asymmetry between the patient and the caregiver is also focussed on. Much consultation research and research from a gender perspective is found here. The political scientific rationality holds action and change as significant constituents.

\section{Understanding the resistance to a gender perspective in medicine}

In the original article on the theoretical model, Johansson concludes that a scientific community as a whole is rational when the different research approaches respect each other and when there is an interaction between the different sub-rationalities [31]. He states:

"It does not matter too much, then, if some scientists doing normal science are stubborn or dogmatic. Neither does it matter much if some theoreticians working with paradigm conflicts are highly speculative and totally insensitive to empirical findings. Nor does it matter if some scientists... merely think in terms of usefulness ... as long as there is an interaction between the different kinds of rationalities".

As we see it, medical science is not quite there yet. There is a clear hierarchy between different medical research fields. Basic research and, to some extent, traditional clinical research, are classified as genuine medical science. There is a special group of distinguished scientific journals with high impact, publishing preferably basic medical research. Lately, medical journals have also shown an increasing interest in clinical research where results can help combat global health problems in the developing as well as in the industrial world [31,32]. The other two research approaches, medical philosophy and 'empowering' research, are often considered as metaphysics or politics by authorities in medical academia, i.e. as something other than science.

Similarly, this has probably been the attitude encountered when trying to introduce into medicine the concept of gender as something more than biological sex. Attempts have ended up outside the prevailing paradigm, a low-status area, sometimes even ruled as non-scientific. The tradition of positivistic science seems to be a strong excuse for making medical research and medical education 'immune' to the gender discussion taking place in the academic world in other disciplines, and in society at large [24].

Representatives of biomedicine and those of a gender perspective not only compete for fame, esteem and resources; there is a wider conflict where biomedicine often claims the right to define the field and to preserve (gendered) privileges. To redefine gender as being synonymous with biological sex is one way to exert such rights. Unfortunately, such claims limit the scientific rationality of medicine. Biomedicine did not produce 'truth-likeness' for a series of important diseases until a gender perspective appeared and was used. We argue that a medical science with gender bias has a suboptimal scientific rationality.

\section{A wider application of the model}

As exemplified in this paper, the theoretical model gave us a better understanding of the resistance to a gender perspective in clinical and academic medicine. This understanding has given us tools to use when handling gender issues in our work as faculty members and researchers.

We suggest that the model can be applied in a wider medical context when different research traditions collide and when misunderstandings between them arise, leading to the risk of restriction in the ways to gain 'truth-likeness' and thereby to a reduced scientific rationality. One example would be when there is scepticism about the scientific rigour of qualitative methods. Used in this way, the model could contribute to shape a medical community where pluralism is seen as a fruitful scientific challenge and benefit, not as a non-scientific disturbance or threat.

\section{Conclusion}

- Research has revealed gender bias in many areas of clinical and academic medicine.

- To avoid such bias a gender perspective in medicine is needed.

- Resistance, difficulties and hard work have been reported from attempts to introduce gender issues into the medical world.

- The structures and hierarchies of medical science, where the biomedical framework dominates, can unfortunately contribute to negative attitudes to gender issues and a gender perspective in the medical society and thereby to gender bias.

- More scientific pluralism in medical science may help prevent gender bias in medicine. 


\section{Competing interests}

The author(s) declare that they have no competing interests.

\section{Authors' contributions}

This article is an extension of a section in the thesis by GR 'I am solely a professional - neutral and genderless': On gender bias and gender awareness in the medical profession (Umeå University 2004). KH and EJ were supervisors for GR while working on the thesis. All three authors contributed to the conception, design, and drafting of this article. GR was responsible for the final draft of the article.

\section{Acknowledgements}

The research by GR on gender bias was supported by grants from the Swedish Medical Research Council, the Swedish Council for Planning and Co-ordination of Research, and the Umeå Medical District, County Council of Västerbotten.

\section{References}

I. Rubin G: The traffic in women: notes on the political economy of sex. In Toward an anthropology of women Edited by: Reiter RR. New York: Monthly Review Press; 1975:157-210.

2. Moynihan C: Theories in health care and research. Theories of masculinity. BM] 1998, 3 I 7:1072-1075.

3. West C, Zimmerman DH: Doing gender. Gender Soc 1987, I:|25-|5|.

4. Cassel J: Doing gender, doing surgery: women surgeons in a man's profession. Hum Organ 1997, 56(I):47-52.

5. Council on Ethical and Judicial Affairs, American Medical Association: Gender disparities in clinical decision making. JAMA 1991, 266(4):559-62.

6. Ruiz MT, Verbrugge LM: A two way view of gender bias in medicine. J Epidemiol Commun Health 1997, 5 I (2): I06- 109.

7. Daly C, Clemens F, Lopes Sendon JL, Tavazzi L, Boersma E, Danchin N, Delahaye F, Gitt A, Julian D, Mulcahy D, Ruzyllo W, Thygessen K, Verheugt F, Fox KM: Gender differences in the management and clinical outcome of stable angina. Circulation 2006, I I 3:490-498.

8. Olfson M, Zarin DA, Mittman BS, Mclntyre JS: Is gender a factor in psychiatrists' evaluation and treatment of patients with major depression? J Affect Dis 200I, 63:149-I57.

9. Raine R: Does gender bias exist in the use of specialist care? J Health Serv Res Policy 2000, 5(4):237-249.

10. Herold AH, Riker Al, Warner EA, Woodard LJ, Brownlee HJ Jr, Pencev D, Oldenski RJ, Brady PG: Evidence of gender bias in patients undergoing flexible sigmoidoscopy. Cancer Detect Prev |997, 2 I(2): |4|-|47.

II. Hamberg K, Risberg G, Johansson EE, Westman G: Gender bias in physicians' management of neck pain: a study of the answers in a Swedish national examination. J Womens Health Gend Based Med 2002, I I (7):653-666.

12. Hamberg K, Risberg G, Johansson EE: Male and female physicians show different patterns of gender bias. A paper-case study of management of irritable bowel syndrome. Scand J Public Health 2003, 3 I:I-9.

13. Bickel J: Gender equity in undergraduate medical education: A status report. I Womens Health Gend Based Med 200I, I0(3):26I-270.

14. Kvaerner KJ, Aasland OG, Botten GS: Female medical leadership: cross sectional study. BM] 1999, 3 1 8:91-94.

15. Reichenbach L, Brown H: Gender and academic medicine: impacts on health workforce. BM/ 2004, 329:792-795.

16. Wennerås $C$, Wold $A$ : Nepotism and sexism in peer-review. Nature 1997, 3 I 5: | 468.

17. Kim IS, Nafsiger AN: Is it sex or is it gender? Clin Pharmacol Ther 2000, 68(I): I-3.

18. Yamamatova A, Starec M, et al.: Anticipation of acute stress in isoprenalin-sensitive and -resistant rats: Strain and gender differences. Pharmacol Toxicol 2000, 87(4): |6I-I68.
19. Alexanderson K, Wingren G, Rosdal I: Gender analyses of medical textbooks on dermatology, epidemiology, occupational medicine and public health. Educ Health I998, I I(2): I I I- I63.

20. Lent B, Bishop JE: Sense and sensitivity: developing a gender issues perspective in medical education. J Womens Health 1998 , 7(3):339-342.

21. Phillips SP: Evaluating women's health and gender. Am J Obst Gynecol 2002, I 87(Suppl 3):22-24.

22. Verdonk $P$, Mans LJL, Largo-Jensen ALM: Integrating gender into a basic medical curriculum. Med Educ 2005, 39: I | | 8- | I 25.

23. Hamberg K, Johansson EE: Medical students' attitudes to gender issues in the role and career of physicians. A qualitative study conducted in Sweden. Med Teach in press.

24. Norstedt M, Davies K: Medical education seemingly immune to discussions of gender. Study indicates gender perspective in teaching is lacking [In Swedish, summary in English]. Läkartidningen 2003, 100:2056-2062.

25. Westerståhl A, Andersson M, Söderström M: Gender in medica curricula: Course organizer views of a gender-issues perspective in medicine in Sweden. Women Health 2003, 37(4):35-47.

26. Risberg G: I am solely a professional - neutral and genderless. On gender bias and gender awareness in the medical profession. In PhD Thesis Umeå: Print \& Media, Umeå University; 2004.

27. Johansson I: Pluralism and rationality in the social sciences. Phil Soc Sci I99I, 2 I (4):427-443.

28. Hamberg K, Johansson E, Lindgren G, Westman G: Scientific rigour in qualitative research - examples from a study of women's health in family practice. Fam Pract 1994, I I(2): I76- I8I.

29. Malterud $\mathrm{K}$ : The art and science of clinical knowledge: evidence beyond measures and numbers. Lancet 2001, 358:397-400

30. Johansson EE, Hamberg K, Westman G, Lindgren G: The meanings of pain: an exploration of women's descriptions of symptoms. Soc Sci Med 1999, 48: I79|-1802.

31. Haines A, Victoria C, Horton R: The Lancet's series on healthsystems research: a call for papers. Lancet 2004, 363:26I-262.

32. Beaglehole R, Horton R: Chronic diseases of adults - a call for papers. Lancet 2005, 365:1913-1914.

\section{Pre-publication history}

The pre-publication history for this paper can be accessed here:

http://www.biomedcentral.com/1741-7015/4/20/prepub

Publish with Bio Med Central and every scientist can read your work free of charge

"BioMed Central will be the most significant development for disseminating the results of biomedical research in our lifetime. "

Sir Paul Nurse, Cancer Research UK

Your research papers will be:

- available free of charge to the entire biomedical community

- peer reviewed and published immediately upon acceptance

- cited in PubMed and archived on PubMed Central

- yours - you keep the copyright

BioMedcentral 